\title{
Óleos essenciais como substituintes de antibióticos promotores de crescimento em frangos de corte: perfil de soroproteínas e peroxidação lipídica
}

\author{
Essential oils as substitutes for antibiotic growth promoters in broilers: soroproteins \\ profile and lipid peroxidation
}

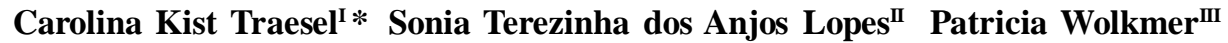 \\ Candice Schmidt $^{\mathrm{I}}$ Janio Morais Santurio $^{\mathrm{IV}}$ Sydney Hartz Alves $^{\mathrm{IV}}$
}

\section{RESUMO}

Os óleos essenciais são alternativas ao uso de promotores de crescimento antibióticos na avicultura, devido à sua ação antimicrobiana, além de possuírem propriedades antioxidante e imunomoduladora. Este estudo foi realizado com o objetivo de avaliar o efeito da suplementação dietética de três doses de óleos essenciais (OLES) de orégano (Origanum vulgare L.), sálvia (Salvia officinalis L.), alecrim (Rosmarinus officinalis L.) e extrato de pimenta (Capsicum frutescens $\boldsymbol{L}$.) em frangos de corte, pela análise do perfil eletroforético de soroproteínas e da peroxidação lipídica plasmática. Os animais $(n=910)$ foram alocados de forma aleatória em cinco tratamentos, com sete repetições de 26 aves cada: o grupo controle (Tc), que recebeu dieta basal sem aditivos; o grupo que recebeu promotor de crescimento antibiótico na dieta (Tatb); e os grupos T50, T100 e T150, alimentados com OLES na doses de 50, 100 e $150 \mathrm{mg} \mathrm{kg}^{-1}$, respectivamente. Aos 42 dias de idade, sete animais foram aleatoriamente selecionados (um de cada repetição) para o estudo do perfil eletroforético de soroproteínas e para a avaliação da peroxidação plasmática de lipídeos, pelo teste de formação de substâncias reativas ao ácido tiobarbitúrico (TBARS). Houve diminuição na concentração de globulinas totais no T150 e na fração betaglobulina nos grupos Tatb e $T 150$ em relação ao grupo controle e ao T50 $(P<0,05)$. Além disso, os níveis de TBARS plasmático foram menores nos grupos que receberam OLES em comparação ao $T c(P<0,05)$. Dessa forma, pode-se inferir que o efeito dos OLES, na maior dose administrada, sugere menor estímulo ao sistema inume humoral de frangos de corte, assim como acontece com a suplementação de promotores de crescimento antibióticos. Adicionalmente, ocorre menor peroxidação plasmática de lipídios e, consequentemente, menos dano oxidativo em frangos de corte, em resposta ao uso dos OLES.
Palavras-chave: orégano, sálvia, alecrim, extrato de pimenta, eletroforese, TBARS.

\begin{abstract}
Essential oils are an alternative to growth promoters based on antibiotics used in animal diets, due to its antimicrobial potential, and immunomodulatory properties. Serum proteins electrophoresis and plasma lipid peroxidation were evaluated in broilers fed with diets supplemented with antibiotics or essential oils from oregano (Origanum vulgare L.), sage (Salvia officinalis L.), rosemary (Rosmarinus officinalis $\boldsymbol{L}$.) and pepper (Capsicum frutescens $\boldsymbol{L}$.) crude extract (OLES). The animals $(n=910)$ were distributed within five treatment groups and seven replicates containing 26 birds each one: control group (diet without additives); the group receiving an antibiotic growth promoter diet (Tatb); and the groups T50, T100 and T150 (supplemented with 50, 100 and $150 \mathrm{mg} \mathrm{kg}^{-1}$ of OLES, respectively). After 42 days, seven animals were randomly selected for serum proteins electrophoretic fractionation and plasma lipid peroxidation evaluation by thiobarbituric acid reactive species (TBARS) test. Total globulins (T150), betaglobulin fraction (Tatb and T150) and plasma TBARS levels in the groups that received OLES $(P<0.05)$ presented a decrease in relation to the control group. These results suggests lower stimulus to the humoral immune response at the higher dose of OLES, as occurred in the antibiotic growth promoter group. Moreover, it suggests lower lipid peroxidation and, consequently, lower oxidative damage caused by OLES use in broiler chickens.
\end{abstract}

Key words: oregano, sage, rosemary, pepper extract, electrophoresis, TBARS.

'Programa de Pós-graduação em Medicina Veterinária da Universidade Federal de Santa Maria (UFSM), 97105-900, Santa Maria, RS, Brasil. E-mail: ninak131@yahoo.com.br.*Autor para correspondência.

"Departamento de Clínica de Pequenos Animais, UFSM, Santa Maria, RS, Brasil.

IIIPrograma de Pós-graduação em Bioquímica Toxicológica, UFSM, Santa Maria, RS, Brasil.

${ }^{\text {IV }}$ Departamento de Microbiologia e Parasitoloia, UFSM, Santa Maria, RS, Brasil. 


\section{INTRODUÇÃO}

A utilização de promotores de crescimento à base de agentes antibacterianos na dieta é uma prática frequente e rotineira na avicultura por propiciar maior desempenho produtivo. No entanto, o uso desses antibióticos vem sofrendo restrições nos últimos anos, devido à possibilidade de seleção de microorganismos resistentes, desenvolvimento de resistência bacteriana cruzada em humanos e devido à exigência de produtos livres de resíduos de antibióticos pelo mercado consumidor (BUTAYE et al., 2003; SALEHAe al., 2009). Como alternativa, tem-se a substituição por metabólitos secundários de plantas como os óleos essenciais, já que eles possuem potencial antimicrobiano (FARAG et al., 1989; KAMEL, 2000; TZAKOU et al., 2001), além de possuírem função imunomoduladora (MELLOR, 2000), propriedades antioxidantes e de conservação dos alimentos (FARAG et al., 1989; BOTSOGLOU et al., 2002). Recentemente, foi demonstrado que frangos de corte alimentados com óleos essenciais de orégano, sálvia, alecrim e extrato de pimenta (OLES) obtiveram peso final e ganho de peso similares àqueles observados em animais suplementados com antibióticos promotores de crescimento. No entanto, a mistura OLES pode ocasionar efeitos tóxicos em frangos quando aplicada em altas dosagens (TRAESEL et al., 2010).

A técnica de eletroforese permite a determinação das frações protéicas presentes no soro ou no plasma. As proteínas plasmáticas são importantes na manutenção da pressão coloidosmótica do sangue, no transporte de minerais e hormônios, na constituição de enzimas e do sistema imunológico do organismo (LASSEN, 2007). A relação entre as frações individuais de proteínas reflete o estado de saúde das aves, salientando a importância e confiabilidade de aplicação do perfil eletroforético de soroproteínas como auxílio no diagnóstico de diversas doenças em aves (WERNER \& REAVILL, 1999), podendo ser utilizado para estimar a função imunológica.

A peroxidação lipídica pode ser induzida pela formação de radicais livres e/ou espécies reativas de oxigênio, processo denominado estresse oxidativo (HALLIWELL \& CHIRICO, 1993). A utilização de antioxidantes para tratar e controlar processos de oxidação de lipídios e proteínas vem sendo preconizada na alimentação de frangos (FELLENBERG \& SPEISKY, 2006), principalmente o uso de antioxidantes naturais (LAGOURI \& BOSKOU, 1995), como os óleos essenciais, pois o uso de antioxidantes sintéticos na nutrição animal vem sofrendo restrições (VALENZUELA et al., 2003). A atividade antioxidante in vitro do óleo essencial de orégano (LAGOURI \& BOSKOU, 1995) e de alecrim (WANG et al., 2008) já foi demonstrada, e o efeito protetor de diversos produtos tem sido pesquisado para amenizar a oxidação/ peroxidação na carne de frango, como o orégano (BOTSOGLOU et al., 2002), a sálvia e o alecrim (FARAG et al., 1989; LOPEZ-BOTE et al., 1998). Porém, estudos avaliando a peroxidação lipídica plasmática in vivo ainda são escassos.

Considerando que os OLES podem ser substitutos de promotores de crescimento antibióticos (TRAESEL et al., 2010) e buscando investigar suas atividades sobre o metabolismo de frangos de corte, o objetivo deste estudo foi avaliar os efeitos da suplementação na dieta de três doses de uma mistura de óleos essenciais de orégano, sálvia, alecrim e extrato de pimenta em frangos de corte, pela análise do perfil eletroforético de soroproteínas e peroxidação lipídica plasmática, em comparação a dietas acrescidas ou não de antibióticos.

\section{MATERIAL E MÉTODOS}

Animais e local: novecentas e dez aves de corte de um dia de idade, com peso médio de 42 gramas, machos, linhagem Cobb, permaneceram sob temperatura de aproximadamente $33^{\circ} \mathrm{C}$ durante a primeira semana de vida, sendo reduzida gradualmente até a temperatura ambiente $\left(24\right.$ a $\left.25,5^{\circ} \mathrm{C}\right)$ após esse período, e sob luminosidade natural. Os animais foram alojados em um galpão, distribuídos em 35 boxes de 26 animais (sete boxes por grupo) com cama de maravalha, os quais receberam ração e água à vontade, com reposição a cada 24 horas, até 42 dias de idade.

Grupos experimentais e alimentação: as aves foram aleatoriamente alocadas em cinco tratamentos, com sete repetições de 26 aves por tratamento. O tratamento controle (Tc) foi constituído por aves que receberam a dieta basal, ração com ingredientes à base de milho, farelo de soja e microelementos (Tabela 1). No segundo tratamento, promotores de crescimento à base de antibiótico (Sulfato de colistina + Oxitetraciclina $0,005 \%$ ) foram acrescidos à ração, de acordo com instruções do fabricante, constituindo o tratamento Tatb. Nos tratamentos T50, T100 e T150, foi acrescida à ração sem antibióticos uma mistura de óleos essenciais microencapsulados de orégano, sálvia, alecrim e extrato alcoólico de pimenta (OLES), na proporção de $50 \mathrm{mg} \mathrm{kg}^{-1}$, $100 \mathrm{mg} \mathrm{kg}^{-1}$ e $150 \mathrm{mg} \mathrm{kg}^{-1}$, respectivamente.

Óleos essenciais e extrato de pimenta: os OLES foram produzidos pelo Laboratório de Pesquisas Micológicas, a partir de orégano (Origanum vulgare 
Tabela 1 - Composição e perfil nutricional da dieta basal de frangos de corte conforme as fases de crescimento

\begin{tabular}{|c|c|c|c|c|}
\hline \multirow{2}{*}{ Ingredientes $(\%)$} & \multicolumn{4}{|c|}{ - } \\
\hline & $1-7$ & $8-21$ & $22-35$ & $36-42$ \\
\hline Milho Grão & 56,54 & 57,70 & 59,70 & 61,99 \\
\hline Farelo de Soja $(45,27 \%$ PB $)$ & 36,85 & 35,64 & 33,21 & 30,80 \\
\hline Óleo Vegetal & 2,57 & 2,81 & 3,26 & 3,62 \\
\hline Fosfato Bicálcico & 1,81 & 1,76 & 1,78 & 1,69 \\
\hline Calcário & 1,04 & 0,95 & 0,96 & 0,90 \\
\hline $\mathrm{Sal}(\mathrm{NaCl})$ & 0,40 & 0,40 & 0,40 & 0,40 \\
\hline Premix Vit/Min sem APC & 0,50 & 0,50 & 0,50 & 0,50 \\
\hline L-Lisina & 0,08 & 0,06 & 0,04 & 0,00 \\
\hline DL-Metionina & 0,11 & 0,08 & 0,06 & 0,00 \\
\hline \multicolumn{5}{|l|}{ Nutrientes } \\
\hline $\mathrm{PB}(\%)$ & 22,00 & 21,00 & 20,50 & 19,50 \\
\hline Energia Metabolizável $\left(\mathrm{kcal} \mathrm{kg}^{-1}\right)$ & 2970 & 3000 & 3050 & 3100 \\
\hline Cálcio $(\%)$ & 1,00 & 0,95 & 0,95 & 0,90 \\
\hline Fósforo disponível (\%) & 0,45 & 0,44 & 0,44 & 0,42 \\
\hline Lisina $(\%)$ & 1,30 & 1,25 & 1,16 & 1,06 \\
\hline TSAA $(\%)$ & 0,92 & 0,88 & 0,83 & 0,75 \\
\hline Treonina $(\%)$ & 0,84 & 0,82 & 0,79 & 0,75 \\
\hline Triptofano $(\%)$ & 0,23 & 0,22 & 0,21 & 0,20 \\
\hline
\end{tabular}

A dieta basal foi administrada a todos os grupos experimentais; frangos de corte suplementados com antibióticos (Tatb) receberam premix de Vitaminas/Minerais $(0,50 \%)$ com promotor de crescimento antibiótico (APC); óleos essenciais de orégano, sálvia, alecrim e extrato de pimenta foram adicionados à dieta dos grupos T50, T100 e T150, nas proporções de $0,005-0,0100$ e $0,015 \%$, respectivamente. A composição da dieta foi completada (100\%) com a adição de Caulim $(0,100 \%$ no grupo controle e Tatb; 0,095 - 0,090 e 0,085\% no T50, T100 e T150, respectivamente).

PB - proteína bruta; TSAA - aminoácidos sulfurados totais.

L.), sálvia (Salvia officinalis L.), alecrim (Rosmarinus officinalis L.) e pimenta malagueta (Capsicum frutescens $L$.), escolhidos de acordo com sua disponibilidade e viabilidade. O processamento, extração e composição química dos óleos essenciais estão descritos em detalhes por POZZATTI et al. (2008). A extração da pimenta foi realizada segundo técnica descrita por LI et al. (2009). Os OLES foram microencapsulados devido a sua volatilidade e para possibilitar uma mistura homogênea na ração, sendo o carvacrol o componente majoritário da mistura.

Colheita de amostras: aos 42 dias de idade, sete animais de cada grupo (um de cada repetição), foram aleatoriamente selecionados e abatidos após insensibilização por corrente elétrica. Foram colhidas amostras de sangue por punção cardíaca. Cerca de $6 \mathrm{~mL}$ de sangue foram armazenados em frascos sem anticoagulante. $\mathrm{O}$ soro foi obtido por centrifugação e parte foi estocada à $-20^{\circ} \mathrm{C}$ para posterior análise do perfil eletroforético das proteínas séricas. Uma alíquota de $4 \mathrm{~mL}$ de sangue, adicionada a tubos contendo $0,4 \mathrm{~mL}$ de heparina sódica (Liquemine ${ }^{\circledast} 5000 \mathrm{UI} \mathrm{mL}{ }^{-1}$, Roche, Rio de Janeiro, Brasil), foi centrifugada para obtenção do plasma, estocado a $-20^{\circ} \mathrm{C}$ até a realização do teste de formação de substâncias reativas ao ácido tiobarbitúrico (TBARS).

Eletroforese de soroproteínas e Peroxidação lipídica: a concentração sérica de proteínas totais (PT) foi realizada em analisador semi-automático (Thermo Plate Analyzer ${ }^{\circledast}$ TP, China), pelo método do biureto, utilizando-se kits comerciais (Labtest ${ }^{\circledR}$ Diagnóstica S.A., Lagoa Santa/MG, Brasil). O fracionamento eletroforético de soroproteínas foi realizado utilizandose fitas de acetato celulose de $2,5 \times 14 \mathrm{~cm}\left(\right.$ Cellogel ${ }^{\circledR}$ Electrophoresis CO., Malta Chemetron, Milão, Itália), em cuba para eletroforese a $220 \mathrm{~V}$ por $20 \mathrm{~min}$, conforme descrito por FRIEDMAN (1961). Para obtenção dos perfis de proteína, procedeu-se a leitura da migração das bandas, após o escaneamento das fitas, utilizandose uma unidade leitora (Denscan ${ }^{\circledR}$ Electrophoresis System, Labex S/A Indústria e Comércio, Aparecida de Goiânia/GO, Brasil), segundo orientações do fabricante. O programa calculou o valor das frações eletroforéticas e a relação albumina : globulinas (A/G), a partir dos níveis de PT mensurados previamente. A quantidade total de globulinas (GLOB) foi obtida somando-se as 
frações eletroforéticas, exceto albumina (ALB). A técnica foi realizada em duplicata para todas as amostras. A peroxidação plasmática de lipídeos foi determinada por meio do teste TBARS, por espectrofotometria a $535 \mathrm{~nm}$, conforme técnica descrita por YOSHIOKA et al. (1979).

Análise estatística: o efeito de cada tratamento foi avaliado por análise de variância de um fator utilizando-se o PROC GLM (General Linear Models Procedure). Sempre que verificado um efeito do tratamento na variável dependente, a diferença entre cada grupo foi analisada pelo teste least squares means. Todas as variáveis dependentes foram testadas para normalidade utilizando-se o teste Shapiro-Wilk e, sempre que necessário, foram normalizadas de acordo com a distribuição dos dados. As análises foram realizadas utilizando-se o pacote estatístico SAS (SAS Institute, Cary, NC, USA) com nível de significância $5 \%(\mathrm{P}<0,05)$.

\section{RESULTADOS E DISCUSSÃO}

Os efeitos dos OLES em frangos de corte foram investigados pela eletroforese de soroproteínas, técnica que permitiu a visualização das frações protéicas ALB, alfaglobulinas 1 e 2 ( $\alpha-1$ e $\alpha-2)$, betaglobulinas ( $($-glob) e gamaglobulinas ( $\gamma$-glob). Não foi observada diferença nos níveis séricos de PT, porém ocorreu uma diminuição significativa na quantidade de GLOB no grupo T150 em relação ao grupo Tc $(\mathrm{P}<0,05)$ e T50 (P<0,005; Figura 1A). A fração ß-glob teve valores significativamente menores nos grupos Tatb e T150, comparados ao grupo $\mathrm{Tc}(\mathrm{P}<0,05)$. O grupo Tatb também demonstrou a fração ß-glob diminuída em relação ao $\mathrm{T} 50(\mathrm{P}<0,05)$, da mesma forma que $\mathrm{T} 150$ teve resultados menores que $\mathrm{T} 50$ ( $\mathrm{P}<0,001$; Figura 1B). Os valores das frações ALB, $\alpha-1, \alpha-2$ e $\gamma$-glob, assim como a relacão A/ $G$, não variaram significativamente.

A diminuição nas globulinas totais mensuradas no T150 ocorreu devido a um decréscimo nas betaglobulinas. No entanto, apesar de as betaglobulinas estarem diminuídas também no Tatb, essa alteração não reduziu significativamente a concentração de globulinas totais nesse grupo. As globulinas têm um papel importante na imunidade em aves (GHAZALAH \& ALI, 2008). Menores concentrações de betaglobulinas ou gamaglobulinas na ausência de hipoalbuminemia quase sempre decorrem de menor teor de imunoglobulinas (Ig). A fração ß-glob é constituída em sua grande maioria pela transferrina e ferritina, responsáveis pela absorção de ferro, lipoproteínas (que transportam lipídeos) e por diversas proteínas de fase aguda. Moléculas de Ig em

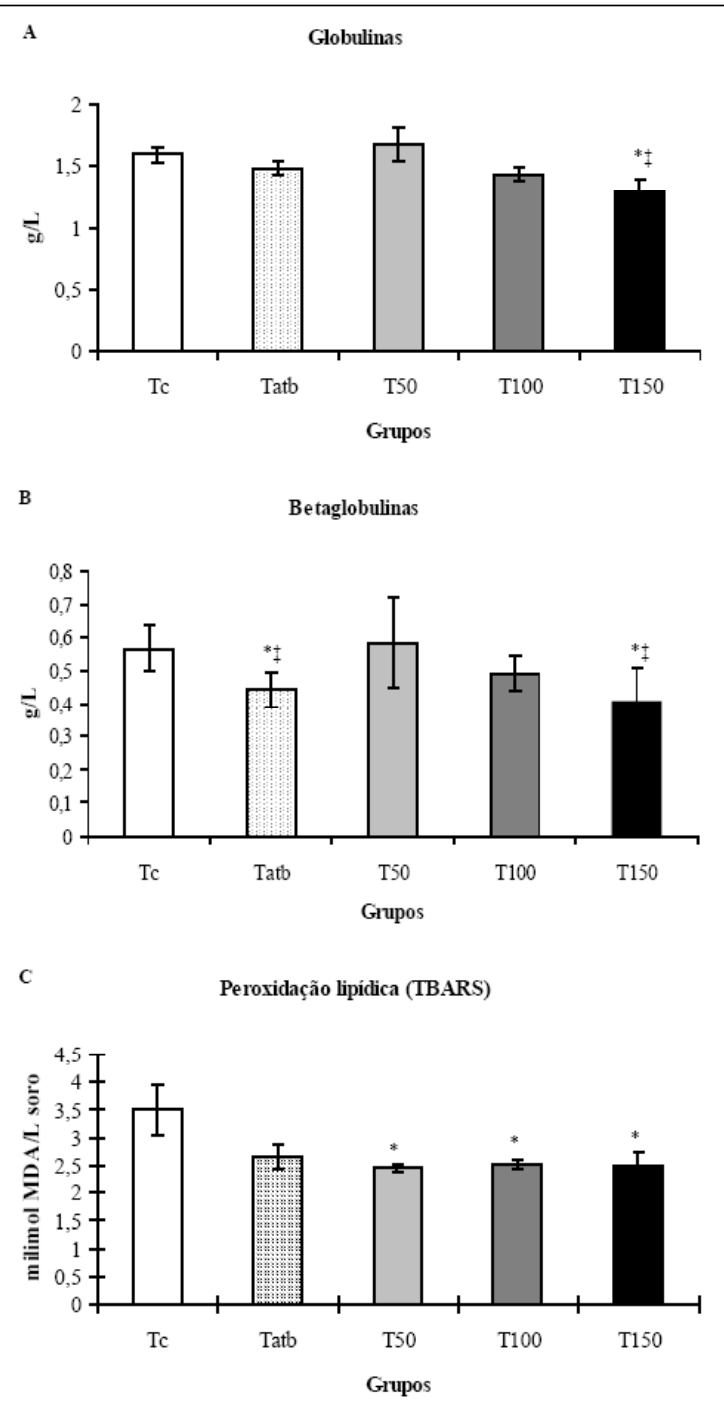

Figura 1 - Valores médios e erro padrão de globulinas (A) e da fração betaglobulina (B), mensurados por eletroforese de soroproteínas, e peroxidação lipídica plasmática $(\mathrm{C})$, determinada pela quantificação de malondialdeído (MDA) e avaliada pelo teste de formação de substâncias reativas ao ácido tiobarbitúrico (TBARS), em frangos de corte aos 42 dias de idade que receberam dieta basal (Tc), suplementada com antibióticos (Tatb) ou com óleos essenciais de orégano, sálvia, alecrim e extrato de pimenta, nas doses de 50 (T50), 100 (T100) e 150mg $\mathrm{kg}^{-1}$ (T150).

* representa diferença estatística $(\mathrm{P}<0,05)$, quando comparado ao Tc;

† representa diferença estatística $(\mathrm{P}<0,05)$, quando comparado ao T50.

A diferença entre cada grupo $(n=7)$ foi analisada pelo teste least squares means, utilizando-se o pacote estatístico SAS (SAS Institute, Cary, NC, USA). Note as escalas diferentes entre os gráficos. 
aves (IgM e IgA) podem migrar da fração $\gamma$-glob para a $\beta$-glob durante o fracionamento eletroforetico (LASSEN, 2007). Portanto, a diminuição da fração ßglob ocorrida neste estudo possivelmente esteja relacionada a uma diminuição na concentração de Ig no soro dos frangos.

Além de já ter sido relatada a propriedade imunomoduladora dos óleos essenciais (MELLOR, 2000), a atividade antibacteriana exercida pelos extratos de plantas como o orégano (KAMEL, 2000), sálvia (TZAKOU et al., 2001) e alecrim (FARAG et al., 1989) pode estar envolvida nesse menor estímulo sobre o sistema imunológico. As Ig são sintetizadas nos tecidos linfóides somente em resposta a um estímulo antigênico (LASSEN, 2007). Portanto, a menor exposição a patógenos ambientais e comensais ocorrida devido à ação antimicrobiana estimularia menos a resposta imunológica adquirida dos frangos, com consequente menor produção de Ig. Efeito negativo sobre o sistema imunológico também foi encontrado no estudo de GHAZALAH \& ALI (2008), no qual frangos de corte alimentados com folhas secas de alecrim foram imunizados com hemácias de ovino, havendo redução no título de anticorpos para essas células e no tamanho do timo. A diminuição da fração ß-glob (e Ig) foi evidente no grupo tratado com promotor de crescimento antibiotico (Tatb) e no grupo que recebeu a maior dose de OLES (T150), sugerindo uma ação antibacteriana dos OLES na maior dose, equivalente à dos agentes bactericidas. No entanto, apesar do provável maior efeito antibiótico dos OLES a 150 $\mathrm{mg} \mathrm{kg}^{-1}$, essa dose pode induzir prejuízo da função renal e hepática em frangos de corte, não produzindo índices de desempenho satisfatórios, como já descrito por TRAESEL et al. (2010).

A peroxidação plasmática de lipídios foi determinada pela quantificação de malondialdeído (MDA), um dos principais produtos finais da peroxidação dos ácidos graxos, que reage com o ácido tiobarbitúrico (YOSHIOKA et al., 1979). Os níveis de TBARS plasmáticos obtidos neste trabalho, a partir da concentração de MDA, indicam que a peroxidação lipídica foi maior no grupo Tc em relação aos grupos T50, T100 e T150 (P<0,05; Figura 1C). Essa menor peroxidação lipídica nos grupos tratados com OLES deve estar relacionada ao possível efeito antioxidante provocado pelos OLES, já que essa propriedade já foi encontrada em diversos óleos essenciais. Investigação in vitro pelo TBARS e outros métodos comprovam que o óleo essencial de orégano, contendo carvacrol (LAGOURI \& BOSKOU, 1995), e o de alecrim (WANG et al., 2008) possuem atividade antioxidante significativa. A propriedade antioxidante dos extratos de plantas está relacionada principalmente com a presença de grupos fenólicos na sua estrutura (HUI, 1996), como nos componentes ativos presentes no alecrim (FARAG et al., 1989). No entanto, flavonóides e terpenóides, presentes no orégano, também apresentam atividade antioxidante. Essas substâncias podem interceptar e neutralizar radicais livres, prevenindo a propagação do processo oxidativo (HUI, 1996). Além disso, a própria ação antibacteriana dos óleos essenciais (FARAG et al., 1989; KAMEL, 2000; TZAKOU et al., 2001) pode ter auxiliado na diminuição da peroxidação de lipídios, já que, durante a fagocitose de bactérias, ocorre produção de radicais livres (BABIOR, 1984).

Os ácidos graxos poliinsaturados das membranas celulares são degradados pela peroxidação lipídica, com subsequente alteração na integridade da membrana, sugerindo que a peroxidação de lipídios, mediada pelos radicais livres, é uma importante causa de dano e destruição das membranas celulares. Injúria oxidativa na membrana celular é evidenciada pelo aumento na formação do MDA (FREEMAN \& CRAPO, 1982). O teste TBARS, que é utilizado para mensurar o MDA, é o método mais comumente utilizado para avaliar a peroxidação lipídica (ESTERBAUER, 1993) e, portanto, pode ser utilizado para determinar a extensão do dano oxidativo de membranas celulares. Por causar dano tecidual, o aumento na peroxidação lipídica está relacionado a diversas condições patológicas (HALLIWELL \& CHIRICO, 1993). Em frangos de corte, o estresse oxidativo constitui um importante mecanismo que leva a danos biológicos e é considerado como uma das causas de diversas patologias que afetam o seu crescimento. Assim como no animal vivo, a oxidação representa uma das principais causas de deterioração de alimentos para consumo humano (FELLENBERG \& SPEISKY, 2006).

Ainda que o efeito de antioxidantes naturais e o dano oxidativo em alimentos tenham sido amplamente pesquisados (LOPEZ-BOTE et al., 1998; BOTSOGLOU et al., 2002), estudos avaliando a peroxidação lipídica plasmática in vivo são escassos, ratificando a importância da realização deste trabalho e, além disso, evidenciando a necessidade de estudos futuros nesse contexto.

\section{CONCLUSÃO}

O efeito dos OLES, na maior dose administrada, sugere menor estímulo ao sistema inume humoral de frangos de corte, evidenciado pelo seu perfil eletroforético de soroproteínas, assim como acontece com a suplementação de promotores de crescimento 
antibióticos. Além disso, o uso de OLES leva à redução da peroxidação plasmática de lipídios e, consequentemente, a menor dano oxidativo em frangos de corte, demonstrando que a substituição de promotores de crescimento por óleos essenciais pode ser uma alternativa viável na avicultura.

\section{COMITÊ DE ÉTICA}

Este estudo foi aprovado pelo Comitê de Ética e Bem-Estar Animal do Centro de Ciências Rurais da Universidade Federal de Santa Maria (CCR/UFSM), n.047/2007, de acordo com legislação vigente e os Princípios Éticos publicados pelo Colégio Brasileiro de Experimentação Animal (COBEA).

\section{AGRADECIMENTOS}

Ao Conselho Nacional de Desenvolvimento Científico e Tecnológico (CNPq, nº 476507/2007-3) e ao Ministério da Ciência e Tecnologia (MCT, 15/2007-Universal), pelo suporte financeiro. Ao Dr. Rogério Ferreira, pela orientação nas análises estatísticas.

\section{REFERÊNCIAS}

BABIOR, B.M. The respiratory burst of phagocytes. Journal of Clinical Investigation, v.73, n.3, p.599-601, 1984.

BOTSOGLOU, N.A. et al. Effect of dietary oregano essential oil on performance of chickens and on iron-induced lipid oxidation of breast, thigh and abdominal fat tissues. British Poultry Science, v.43, n.2, p.223-230, 2002. Disponível em: <http:// w w w. i n f o r m a w o r l d c c o / s m p p / content $\sim \mathrm{db}=$ jour $\sim$ content $=\mathrm{a} 713655185 \sim \mathrm{frm}=\mathrm{abslink}>$. Acesso em: 26 nov. 2010. doi:10.1080/00071660120121436.

BUTAYE, P. et al. Antimicrobial growth promoters used in animal feed: effects of less well know antibiotics on Grampositive bacteria. Clinical Microbiology Reviews, v.16, n.2, p.175188, 2003. Disponível em: <http://cmr.asm.org/cgi/reprint/ 16/2/175>. Acesso em: 26 nov. 2010. doi:10.1128/ CMR.16.2.175-188.2003.

ESTERBAUER, H. Cytotoxicity and genotoxicity of lipidoxidation products. American Journal of Clinical Nutrition, v.57, n.5, p.779S-785S, 1993. Disponível em: <http:// www.ajcn.org/cgi/reprint/57/5/779S>. Acesso em: 31 maio, 2010.

FARAG, R.S. et al. Antimicrobial activity of some Egyptian spice essential oils. Journal of Food Protection, v.52, n.9, p.665-667, 1989.

FELLENBERG, M.A.; SPEISKY, H. Antioxidants: their effects on broiler oxidative stress and its meat oxidative stability. World's Poultry Science Journal, v.62, p.53-70, 2006. Disponível em: $<$ http://journals.cambridge.org/action/displayFulltext?type $=1 \&$ fid= $624180 \&$ jid=WPS \&volumeId $=62$ \&issueId $=01$ \&aid $=624168>$. Acesso em: 26 nov. 2010. doi:10.1079/WPS200584.

FREEMAN, B.A.; CRAPO, J.D. Biology of disease: free radicals and tissue injury. Laboratory Investigation, v.47, n.5, p.412426, 1982.
FRIEDMAN, H.S. A standardized procedure for serum protein eletrophoresis on celulose acetate membrane strips. Clinica Chimica Acta, v.6, n.6, p.775-781, 1961. Disponível em: <http://linkinghub.elsevier.com/retrieve/pii/ 0009898161901656>. Acesso em: 26 nov. 2010. doi:10.1016/ 0009-8981(61)90165-6.

GHAZALAH, A.A.; ALI, A.M. Rosemary leaves as a dietary supplement for growth in broiler chickens. International Journal of Poultry Science, v.7, n.3, p.234-239, 2008. Disponível em: <http://scialert.net/ qredirect.php?doi=ijps. $2008.234 .239 \&$ linkid=pdf $>$. Acesso em: 26 nov. 2010. doi:10.3923/ijps.2008.234.239.

HALLIWELL, B.; CHIRICO, S. Lipid peroxidation: its mechanism, measurement, and significance. American Journal of Clinical Nutrition, v.57, n.5, (Suppl.), p.715S725S, 1993. Disponível em: <http://www.ajen.org/cgi/reprint/ 57/5/715S >. Acesso em: 31 maio, 2010.

HUI, Y.H. Oleoresins and essential oils. In: (Ed). Bailey's industrial oil and fat products. New York: WileyInterscience Publication, 1996. Cap.6, p.145-153.

KAMEL, C. A novel look at a classic approach of plant extracts (special number). Feed Mix - The International Journal on Feed, Nutrition and Technology, v.9, n.6, p.19-24, 2000.

LAGOURI, V.; BOSKOU, D. Screening for antioxidant activity of essential oils obtained from spices. Developments in Food Science, v.37, n.1, p.869-879, 1995. Disponível em: <http:// linkinghub.elsevier.com/retrieve/pii/S0167450106802037>. Acesso em: 26 nov. 2010.doi:10.1016/S0167-4501(06)80203-7.

LASSEN, E.D. Avaliação laboratorial das proteínas do plasma e do soro sangüíneo. In: THRALL, M.A. et al. Hematologia e bioquímica clínica veterinária. São Paulo : Roca, 2007. Cap.26, p.376-390.

LI, F. et al. Preparative isolation and purification of capsaicinoids from Capsicum frutescens using high-speed counter-current chromatography. Separation and Purification Technology, v.64, p.304-308, 2009. Disponível em: <http://assets0.pubget.com/ pdf/pgtmp_0c9cef5a-f227-6806-a6a0-e96b23b290ee.pdf>. Acesso em: 26 nov. 2010. doi:10.1016/j.seppur.2008.10.005.

LOPEZ-BOTE, C.J. et al. Effect of dietary administration of oil extracts from rosemary and sage on lipid oxidation in broiler meat. British Poultry Science, v.39, n.2, p.235-140, 1998. Disponível em: <http://www.ingentaconnect.com/content/tandf/ cbps/1998/00000039/ 00000002/art00011>. Acesso em: 26 nov. 2010. doi: 10.1080/00071669889187.

MELLOR, S. Herbs and spices promote health and growth. Pig Progress, v.16, n.4, p.18-21, 2000.

POZZATTI, P. et al. In vitro activity of essential oils extracted from plants used as spices against fluconazole-resistant and fluconazole-susceptible Candida spp. Canadian Journal of Microbiology, v.54, n.11, p.950-956, 2008. Disponível em: $<\mathrm{http}: / /$ rparticle.web-p.cisti.nrc.ca/rparticle/ AbstractTemplateServlet?calyLang=eng\&journal $=$ cjm\&volume $=$ $54 \&$ year $=0 \&$ issue $=11 \& \mathrm{msno}=w 08-097>$. Acesso em: 26 nov. 2010. doi:10.1139/W08-097.

SALEHA, A.A. et al. Possible effect of antibiotic-supplemented feed and environment on the occurrence of multiple antibiotic 
resistant Escherichia coli in chickens. International Journal of Poultry Science, v.8, n.1, p.28-31, 2009. Disponível em: <http:/ /scialert.net/qredirect.php?doi=ijps.2009.28.31\&linkid=pdf $>$. Acesso em: 26 nov. 2010. doi:10.3923/ijps.2009.28.31.

TRAESEL, C.K. et al. Serum biochemical profile and performance of broiler chickens fed diets containing essential oils and pepper. Comparative Clinical Pathology, In Press, 2010. Disponível em: <http://www.springerlink.com/content/ 55253174871u1255/fulltext.pdf $>$. Acesso em: 26 nov. 2010. doi: $10.1007 / \mathrm{s} 00580-010-1018-1$.

TZAKOU, O. et al. Composition and antimicrobial activity of the essential oil of Salvia ringens. Planta Medica, v.67, n.1, p.81-83, 2001. Disponível em: <https://www.thieme-connect.com/ ejournals/abstract/plantamedica/doi/10.1055/s-2001-10627>. Acesso em: 26 nov. 2010. doi:10.1055/s-2001-10627.

VALENZUELA, A.B. et al. Natural antioxidants in functional foods: from food safety to health benefits. Grasas y Aceites, v.54, n.3, p.295-303, 2003. Disponível em: <http:// grasasyaceites.revistas.csic.es/index.php/grasasyaceites/article/ viewFile/245/246>. Acesso em: 31 maio, 2010.

WANG, W. et al. Antioxidative activity of Rosmarinus officinalis L. essential oil compared to its main components. Food Chemistry, v.108, n.3, p.1019-1022, 2008. Disponível em: <http://linkinghub.elsevier.com/retrieve/pii/ S0308814607011697>. Acesso em: 26 nov. 2010. doi:10.1016/ j.foodchem.2007.11.046.

WERNER, L.L.; REAVILL, D.R. The diagnostic utility of serum protein electrophoresis. Veterinary Clinics of North America: Exotic Animal Practice, v.2, n.3, p.651-662, 1999.

YOSHIOKA, T. et al. Lipid peroxidation in maternal and cord blood and protective mechanism against active-oxygen toxicity in the blood. American Journal of Obstetrics and Gynecology, v.135, n.3, p.372-376, 1979. 